\title{
A new concept to stimulate mucosal as well as systemic immunity by parenteral vaccination as applied to the development of a live attenuated Salmonella enterica serovar Dublin vaccine
}

\author{
Tetsuo Mizuno*, Richard PloEg, Darren TRotT \\ School of Veterinary Science, The University of Queensland, Brisbane, Queensland, 4072, Australia
}

(Received 12 December 2006; accepted 19 April 2007)

\begin{abstract}
A new concept of slow "drip feeding" that enables activation of mucosal as well as systemic immunity following parenteral vaccination was demonstrated using Salmonella Dublin in a mouse model. The live vaccine candidate, N-RM25, generated from a wild $S$. Dublin strain utilising metabolic-drift (spontaneous chromosomal) mutations had a unique sensitivity to bile and restricted growth in the presence of a very low concentration of bile salts No. $3(0.075 \%(\mathrm{w} / \mathrm{v}))$ but also had the ability to survive in a high concentration $(19.2 \%)$ of the substance. Following intraperitoneal administration with $10^{7} \mathrm{cfu}, \mathrm{N}-\mathrm{RM} 25$ colonised and survived $\left(10^{1}-10^{3} \mathrm{cfu} / \mathrm{g}\right)$ in the liver and spleen of mice for over 24 days without causing disease. A small number of the mutant organisms also penetrated the gall bladder and gut, most likely via the enterohepatic circulation. N-RM25 induced significant levels of serum IgG, IgA and intestinal secretory IgA. A second metabolic-drift mutant (R-NM29) that was rapidly eliminated from the liver and spleen and highly unlikely to penetrate the gall bladder and gut, stimulated some systemic immunity, but induced no mucosal immunity because it did not reach the immune stimulation sites within the gut. In vaccine trials, N-RM25 was significantly more effective in eliminating the homologous challenge bacteria ( $S$. Dublin wild strain FD436) from the internal organs and intestinal lumen when compared to R-NM29 and the negative control. N-RM25 prevented the development of systemic infection and produced 100\% protection.
\end{abstract}

Salmonella Dublin / bile / live attenuated vaccine / parenteral vaccination / mucosal immunity

\section{INTRODUCTION}

Salmonella enterica subspecies enterica serovar Dublin ( $S$. Dublin) is a hostadapted bacterium which mainly colonises cattle and calves. Like Salmonella Typhi in humans, it is often invasive and causes enteritis, septicaemia and abortion $[1,14$, $27,31,40]$. Live vaccines confer better immunity against this organism than cur-

\footnotetext{
*Corresponding author: t.mizuno@uq.edu.au
}

rently available vaccines (mostly killed), probably because both systemic and mucosal immunity are important in preventing the disease [17, 28-30,35]. Parenteral vaccines can produce systemic but only poor mucosal immunity [20]. It has been widely held in both medical and veterinary fields that only oral vaccination is suitable for producing efficient mucosal immunity in the gut [11]. This is because it directly stimulates the gut-associated 
lymphoid tissue (GALT) and enhances production of specific IgA $[18,20]$. However, oral vaccination with live organisms represents a challenge in evading the bactericidal effects in the alimentary tract. Ruminants are especially difficult because rumino-reticulum conditions may allow as few as one in one million administered organisms to reach immune stimulation sites in the gut $[2,7]$. To stimulate efficient immunity by oral vaccination, a large vaccine dose and repeated administration are usually required [32,39]. This often results in faecal shedding of vaccine organisms and undesirable clinical signs such as fever and diarrhoea [29, 32, 39]. Various antigen delivery and mucosal immunity stimulation methods, such as particulated and non-particulated adjuvants, have been studied [8, 11]. For ruminants, encapsulation of vaccine antigens in microparticles has been considered an efficient oral delivery method to stimulate intestinal mucosal immunity $[3,11]$. However, a study in cattle showed that from 2.4 to $52.1 \%$ of particles ingested were regurgitated [9] and potentially shed to the environment.

To overcome these difficulties, the slow "drip feeding" hypothesis, a new immunity activation concept, was conceived. The key features are the following: (1) a live vaccine strain administered parenterally will penetrate and colonise a given anatomical region; (2) its growth will be restricted but not prevented by factor(s) normally found in that region; (3) it will survive in the region for a limited period but long enough to stimulate systemic immunity without deleterious side effects; (4) it will also reach anatomical sites where mucosal immunity is stimulated. Applied to $S$. Dublin, the anatomical region for colonisation is the liver and gall bladder, the factor to restrict growth is bile and the anatomical site for mucosal immunity stimulation is the gut. Based on this concept, the following criteria were developed for selection of a live attenuated $S$. Dublin vaccine: (1) restricted growth in the presence of bile; (2) penetration of the liver and gall bladder following parenteral inoculation and colonisation of these organs for a limited period without causing unacceptable clinical side effects, and; (3) demonstrated ability to be shed into the intestine for a limited period in small numbers. If these conditions are met, the live vaccine candidates may avoid bactericidal effects by bypassing the foregut and stimulate both systemic and mucosal immunity without causing disease. In addition, contamination of the environment by live Salmonella would be minimised.

In the work reported here, stable metabolic-drift (spontaneous chromosomal) mutants N-RM25 and R-NM29, isolated from $S$. Dublin wild strain FD436, were tested for conformity to the above criteria. The minimum inhibitory concentration (MIC), minimum bactericidal concentration $(\mathrm{MBC})$ of bile salts (BS: the major constituents of crude bile that affect bacterial growth) and the growth rate in different concentrations of BS were determined. Virulence, chronological studies of tissue penetration and pathogenic effects, immunogenicity and protective properties following intraperitoneal administration were then investigated in a mouse model.

\section{MATERIALS AND METHODS}

\subsection{Isolation of candidate strains}

Candidate strains, nalidixic acid and rifampicin resistant mutant (N-RM25) and rifampicin and nalidixic acid resistant mutant (R-NM29), were previously generated from $S$. Dublin wild strain FD436 (the causative organism of an outbreak of salmonellosis on a dairy farm in Beaudesert, Queensland, Australia in 1998) utilising metabolic-drift (spontaneous chromosomal) mutations induced by nalidixic acid and rifampicin according 
to the method described by Linde [19], with some modifications. Briefly, single antimicrobial-resistant mutants were spontaneously generated by spatulating approximately $10^{10}$ colony forming units (cfu) of FD436 on a sheep blood agar (SBA) plate containing $0.04 \%(\mathrm{w} / \mathrm{v})$ nalidixic acid (Sigma, St. Louis, USA) (SBAN) and then incubating at $37{ }^{\circ} \mathrm{C}$ for $72 \mathrm{~h}$. Strains that became resistant to the antimicrobial were tested for stability by subculturing 10 times on to SBAN plates. Turbidimetry (OD 420-580 nm) was performed in tryptone soya broth (TSB) (Oxoid, Hampshire, United Kingdom) to determine the growth rate of strains maintaining resistance. Approximately $10^{10} \mathrm{cfu}$ of stable, single antimicrobial-resistant mutants with a reduced growth rate were spatulated on to a SBAN plate also containing $0.02 \%(\mathrm{w} / \mathrm{v})$ rifampicin (Sigma) (SBANR) to isolate nalidixic acid-rifampicin double antimicrobial-resistant mutants (N-RM). The same procedure was then repeated to isolate stable N-RM with a reduced growth rate.

The procedure described above was repeated, with the antimicrobials applied in the reverse order, to isolate stable rifampicin-nalidixic acid double antimicrobial-resistant mutants (R-NM) with a reduced growth rate.

The stability of mutation and antimicrobial susceptibility of both N-RM25 and R-NM29 were further evaluated using the following criteria to assess their suitability as a vaccine candidate.

1. Stable resistance to nalidixic acid and rifampicin both following subculturing 50 times on SBA and following passage through a mouse.

2. At least two independent mutations confirmed on the chromosome.

3. No antimicrobial cross-resistance to $\beta$ lactams, cephalosporins, aminoglycosides, tetracycline and fluoroquinolones.

\subsubsection{Stability of resistance to nalidixic acid and rifampicin}

Approximately 300 colonies of each mutant growing on SBA plates both following subculturing 50 times on SBA and following passage through a mouse were transferred onto SBANR plates using the replica plate method [6].

\subsubsection{Genotypic characterisation}

A portion of the gyrA gene (expected approximate size 347 base pairs (bp) [12]) encompassing the quinolone resistancedetermining region (QRDR) [24, 42] was amplified by PCR for FD436 and the mutants using primers, SALGYRA-F (5'-TGTCCGAGATGGCCTGAAGC-3') and SALGYRA-R (5'-TACCGTCATAGTTATCCACG-3') (Genset Pacific Pty., Ltd., Lismore, Australia). A portion of the $r p o B$ gene (expected approximate size 708 bp [22]) encompassing three clusters (I, II and III) which relate to rifampicin resistance [15] was also amplified using primers, SALRPOF3 (5'-TCGGCAACCGTCGTATCCGT-3') and RPOBREV (5'-TCGCACCCATCAACGCACGG-3') (Genset Pacific Pty., Ltd. and Gibco BRL, respectively). The PCR amplification reactions contained 6.4 picomole of each primer, $200 \mu \mathrm{M}$ of each dinucleotide triphosphate, $1 \times$ Expand High Fidelity buffer with $2 \mathrm{mM}$ magnesium chloride (Expand High Fidelity PCR System, Roche) and 1 unit of Expand High Fidelity PCR enzyme mix (Expand High Fidelity PCR System). Cycling conditions of the PCR amplification reaction were an initial denaturation at $94{ }^{\circ} \mathrm{C}$ for $3 \mathrm{~min}$ and then the cycling protocol for 30 cycles (denaturation at $94{ }^{\circ} \mathrm{C}$ for $30 \mathrm{~s}$, annealing at $55^{\circ} \mathrm{C}$ for $30 \mathrm{~s}$ and extension at $68^{\circ} \mathrm{C}$ for $3 \mathrm{~min})$. A final extension was conducted at $72{ }^{\circ} \mathrm{C}$ for $3 \mathrm{~min}$. The reaction products were purified with the QIAquick PCR 
Purification Kit (Qiagen, Germany) and then sequencing reactions were performed using BigDye Ready Reaction DyeDeoxy Terminator Cycle Sequencing kit (Applied Biosystems, USA). The final reaction products were analysed using a 373A DNA Sequencing System at the Australian Genome Research Facility (AGRF), Brisbane, Qld, Australia.

\subsubsection{Antimicrobial disk susceptibility assays}

Antimicrobial sensitivity profiles of FD436 and the mutants were determined in accordance with the method proposed by The National Committee on Clinical Laboratory Standards (NCCLS) [10, 37]. Antimicrobial agents and disk contents used in the tests are as follows. Amoxicillin $(10 \mu \mathrm{g})$, amoxicillin/clavulanic acid $(20 / 10 \mu \mathrm{g}), \quad$ ticarcillin/clavulanic acid $(75 / 10 \mu \mathrm{g})$, cephalothin $(30 \mu \mathrm{g})$, ceftazidime $(30 \mu \mathrm{g})$, gentamicin $(10 \mu \mathrm{g})$, tetracycline $(30 \mu \mathrm{g})$, enrofloxacin $(5 \mu \mathrm{g})$, ciprofloxacin $(5 \mu \mathrm{g})$ and sulphamethoxazole/trimethoprim (1.25/23.75 $\mu \mathrm{g})$.

\subsection{Bile sensitivity assays}

MIC and MBC of BS No. $3(70 \%$ sodium cholate and $30 \%$ sodium deoxycholate) (Oxoid) for FD436 and the mutants were determined by suspending approximately $10^{5} \mathrm{cfu} / \mathrm{mL}$ of each strain in $2 \mathrm{~mL}$ aliquots of TSB media containing graded concentrations of BS No. $3(0.075$, $0.15,0.3,0.6,1.2,2.4,4.8,9.6,14.4,19.2$ and $24 \%(\mathrm{w} / \mathrm{v}))$. BS No. 3 has an ability to inhibit bacterial growth or kill bacteria that is approximately three times greater than crude BS [5]. For determining growth rates and $\mathrm{MIC}$, turbidimetry $\left(\mathrm{OD}_{420-580}\right)$ was performed on each suspension at $37^{\circ} \mathrm{C}$ for $20 \mathrm{~h}$. To determine MBC, each medium containing greater than $2.4 \%$ BS No. 3 was diluted to a concentration of $2.4 \%$ and cultivated on SBA plates at $37{ }^{\circ} \mathrm{C}$ for $48 \mathrm{~h}$.

\subsection{Preparation of vaccine and challenge strains}

Bacterial strains were suspended in phosphate-buffered saline solution (PBS) to a concentration of approximately $10^{7} \mathrm{cfu} / \mathrm{mL}$. Each suspension was flooded onto reduced SBA plates and the plates were anaerobically incubated at $37^{\circ} \mathrm{C}$ for $6 \mathrm{~h}$ (for the wild strain) and $10 \mathrm{~h}$ (for the metabolic-drift mutants). Bacteria growing on each plate were harvested in warm $\left(37^{\circ} \mathrm{C}\right)$ PBS and washed twice with PBS before administration.

\subsection{Experimental infection}

All experiments were performed in accordance with the guidelines of the Animal Ethics Committee of The University of Queensland (Approval numbers VP/684/00 and SVS/004/04/D).

\subsubsection{Determination of 50 percent infectious dose $\left(I_{50}\right)$}

For ethical reasons, the $\mathrm{ID}_{50}$ for each strain was determined instead of the $50 \%$ lethal dose. Three groups (Groups 1, 2 and 3) of forty mice (Salmonella free, Quackenbush out-bred, 3-week old, female mice) were each divided into eight subgroups ( $n=5 /$ subgroup), including an uninoculated control group. Bacterial suspensions containing challenge strains were subjected to six serial ten fold dilutions and administered to mice via the intraperitoneal route. Actual challenge doses of each group were Group 1: $1.1 \times 10^{8}$ to $1.1 \times 10^{2} \mathrm{cfu} / \mathrm{mouse}$ of FD436; Group 2: $5.1 \times 10^{8}$ to $5.1 \times 10^{2} \mathrm{cfu} /$ mouse of N-RM25; and Group 3: $2.7 \times 10^{8}$ to $2.7 \times 10^{2} \mathrm{cfu} / \mathrm{mouse}$ of R-NM29. Clinical appearance (activity, appetite, dehydration, respiration and faecal consistency) of all mice was observed daily for 5 consecutive days post-inoculation (P.I.). Any mice 
showing clinical signs of infection (three or more of the above five parameters) were classed as being infected by $S$. Dublin and immediately euthanised. All surviving mice were euthanised at the end of the observation period. Bacteriological investigation was performed on the heart blood, liver and spleen of all euthanised mice. An $\mathrm{ID}_{50}$ for each strain was calculated as described by Reed and Muench [26].

\subsubsection{Chronological investigation of tissue penetration and pathology}

Forty-four mice were divided into 4 groups $(n=10$ in Group $4, n=20$ in Group 5, $n=10$ in Group 6 and $n=4$ in Group 7). Experimental infection was performed via the intraperitoneal route on Day 0 using the following doses. Group 4: $4.9 \times 10^{1} \mathrm{cfu} /$ mouse of FD436; Group 5: $3.8 \times 10^{7} \mathrm{cfu} /$ mouse of N-RM25; Group 6: $2.7 \times 10^{7} \mathrm{cfu} /$ mouse of R-NM29, and Group 7: uninoculated controls. Clinical appearance was observed for 9-24 consecutive days P.I. Ten faecal pellets were collected daily from each group for bacteriological investigation. At set time points during the experiments (every 2-3 days), two mice in each group were fasted for $4 \mathrm{~h}$ and euthanised. Following post-mortem examination, specimens (heart blood, liver, spleen and gall bladder bile) were aseptically collected from one of the euthanised mice in each group for bacteriological investigation. The liver, spleen and gall bladder of a second mouse in each group were subjected to histopathological examination.

\subsubsection{Isolation and identification of Salmonella}

Specimens were cultured for Salmonella using conventional direct isolation (DI) and identification methods [25]. When Salmonella was not isolated through the DI method, the following enrichment isolation (EI) method was used. Faecal specimens were added to a mannitol selenite broth (MSB) (Oxoid) medium containing $0.0001 \mathrm{~g}$ L-cystine (BDH, Victoria, Australia), and blood and gall bladder bile were inoculated into a cooked meat broth medium. These media were incubated at $37^{\circ} \mathrm{C}$ for $24 \mathrm{~h}$ and then conventional DI methods were repeated.

To distinguish the mutants from the wild strain, all Salmonella isolates were plated on to SBA containing $0.04 \%$ nalidixic acid and $0.02 \%$ rifampicin. To identify each mutant strain, colony morphology on SBA after $24 \mathrm{~h}$ incubation at $37{ }^{\circ} \mathrm{C}(\mathrm{N}-\mathrm{RM} 25$ : circular, raised, matte, translucent colony; R-NM29: circular, convex, glossy, grey, opaque colony), and a carbohydrate fermentation test using glucose and L-(+)arabinose were performed (N-RM25 ferments only glucose without gas; R-NM29 ferments glucose with gas and ferments L(+)-arabinose).

\subsubsection{Quantitative isolation of Salmonella from the liver plus spleen}

Since the challenge bacteria were administered via the intraperitoneal route, the liver and spleen samples were placed in boiling water for $3 \mathrm{~s}$ to sterilise their surfaces. The samples were then weighed, homogenised and mixed with PBS to a total volume of $5 \mathrm{~mL}$. Viable bacterial cells were then determined by serial ten-fold dilution in PBS [23].

\subsubsection{Histopathology}

Tissue samples from the liver, spleen and gall bladder were collected immediately after euthanasia, fixed in $10 \%$ phosphate buffered formalin and then processed by conventional methods for histopathology. The sections were stained with the haematoxylin and eosin (HE) stain and the Giemsa stain, and examined to determine 
the presence of histopathological changes in the liver, spleen and gall bladder and to evaluate the degree of penetration of the gall bladder by the inoculated organisms. Two scoring systems were developed to compare the degree of changes between inoculated groups.

1. Histopathological (HP) score: Based on the level of inflammation, the histopathological changes in the liver, spleen and gall bladder were individually scored on a scale of 0 to 3 .

$0=$ Normal $/$ no detectable changes.

$1=$ Mild changes: A few suppurative foci and/or mild inflammatory infiltrate in the liver and spleen, and one or more of the following changes in the gall bladder. Mild epithelial hyperplasia, mild oedema of the lamina propria (LP), margination of inflammatory cells and mild inflammatory infiltrate.

$2=$ Moderate changes: Moderate degree of one or more of the above changes.

$3=$ Marked changes: Marked degree of one or more of the above changes and/or other severe changes such as vasculitis and coagulative necrosis in the liver and spleen, and marked degree of one or more of the above changes and/or other severe changes such as extension of inflammation to subserosa in the gall bladder.

2. Bacterial penetration (BP) score: The levels of penetration of the gall bladder by the organisms were scored on a scale of 0 to $3(0=$ no penetration, $1=$ penetration of the lumen only, 2 = penetration of mucosa, $3=$ penetration of submucosa).

\subsection{Immunological assays}

Sixty mice were divided into 3 groups (Groups 8, 9 and 10, $n=20 /$ group). Mice in Groups 8 and 9 were administered with N-RM25 $\left(9.8 \times 10^{7} \mathrm{cfu} /\right.$ mouse $)$ and R-NM29 $\left(1.1 \times 10^{8} \mathrm{cfu} /\right.$ mouse $)$, respectively, via the intraperitoneal route on Day 0. Mice in Group 10 served as uninoculated controls. Five mice in each group were fasted for $4 \mathrm{~h}$, sacrificed on Day 0 and then every seven days until Day 21. Upon post-mortem examination, heart blood and intestinal flush samples were collected for serum IgG and IgA determination and secretory IgA determination, respectively, using standard enzyme-linked immunosorbent assay (ELISA) techniques [21].

Intestinal flush samples were collected by washing the lumen of a ligated section containing the ileum and ileocaecum (approximately $15 \mathrm{~cm}$ from immediately before the caecum), processed using a previously described technique [21] and then kept at $-20{ }^{\circ} \mathrm{C}$ until examination.

For the ELISA, whole cells (approximately $10^{9}$ ) of $S$. Dublin FD436 inactivated with $1 \%$ formalin in PBS were used as the antigen. Starting dilutions of samples for $\operatorname{IgG}$ and $\operatorname{IgA}$ were 1:50 and $1: 20$, respectively. All samples were twofold diluted down the plate with diluting buffer (PBS with $0.05 \%$ Tween-20 and $1 \%$ casein sodium salt). Anti-mouse IgG (goat IgG anti-mouse IgG conjugated with horseradish peroxidase (Chemicon)) diluted at 1:5000, or anti-mouse IgA (goat IgG anti-mouse IgA conjugated with horseradish peroxidase (Cappel)) diluted at 1:1500 was added to the corresponding samples. The plates were read in an automated ELISA reader at a wavelength of $450 \mathrm{~nm}$.

\subsection{Vaccine trials with $\mathrm{N}-\mathrm{RM} 25$ and R-NM29}

Eighteen mice were divided into three groups. Mice in Group $11(n=5)$ were vaccinated with N-RM25 on Day $0\left(1.7 \times 10^{7} \mathrm{cfu} /\right.$ mouse $)$ and received a booster vaccination on Day $21\left(1.9 \times 10^{8}\right.$ $\mathrm{cfu} /$ mouse) via the intraperitoneal route. Mice in Group $12(n=8)$ were administered R-NM 29 in doses of $2.7 \times$ $10^{7} \mathrm{cfu} /$ mouse and $1.7 \times 10^{8} \mathrm{cfu} /$ mouse for vaccination (Day 0) and booster vaccination (Day 21), respectively. No vac- 
cines were administered to the control mice (Group 13: $n=5$ ). All mice were challenge exposed via the same route on Day 35 using FD436 with a dose of $4.6 \times 10^{4} \mathrm{cfu} / \mathrm{mouse}$ (approximately 100 times greater than its $\mathrm{ID}_{50}$ ). Clinical observation and bacteriological investigation of the faeces, heart blood, liver and spleen were performed. Mice that survived throughout the 65 day monitoring period were euthanised on Day 66 post-vaccination. The distribution of Salmonella in the internal organs (lung, duodenum, jejunum, ileum, ileocaecum, caecum, colon and kidney) was also examined only on mice which did not yield Salmonella from a heart blood culture, due to the difficulty in distinguishing between actual colonisation of the organs by Salmonella and its temporary presence in the sites via blood circulation.

\subsection{Statistical methods}

The two-tailed Fisher's exact test was used in "Experimental infection" and "Vaccine trials with N-RM25 and RNM29". In "Immunological assays", the two-tailed Mann-Whitney test was utilised. Data were analysed with GraphPad InStat version 3.05 (GraphPad Software, San Diego, USA). The results were considered statistically significant when probability was less than $5 \%(p<0.05)$.

\section{RESULTS}

\subsection{Isolation of candidate strains}

\subsubsection{Stability of resistance to nalidixic acid and rifampicin}

All colonies of each mutant transferred from the original SBA plates grew on SBANR plates.

\subsubsection{Genotypic characterisation}

N-RM25 had a nucleotide substitution of A to $\mathrm{G}$, resulting in aspartic acid (Asp)87 to glycine (Gly) within the amplified portion of gyrA. A nucleotide substitution of $\mathrm{G}$ to $\mathrm{T}$ was identified in gyrA of $\mathrm{R}$ NM29. This substitution caused Gly-81 to cysteine (Cys).

In the amplified portions of rpoB, both N-RM25 and R-NM29 had a nucleotide substitution of $A$ to $G$ at the same position that caused an amino acid substitution of Asp-516 to Gly.

\subsubsection{Antimicrobial disk susceptibility assays}

FD436 and the mutants were susceptible to all antimicrobial agents used in the experiment.

\subsection{Bile sensitivity}

The MIC of BS No. 3 for FD436 was $19.2 \%$ and for N-RM25 and R-NM29 was $14.4 \%$ (estimated corresponding MIC of crude BS for FD436: $57.6 \%$, and for $\mathrm{N}$ RM25 and R-NM29: 43.2\%). The MBC for all strains was $24 \%$ (estimated corresponding MBC: 72\%). The growth of FD436 and R-NM29 was not markedly slowed by BS No. 3 in concentrations of less than $4.8 \%$ (estimated corresponding crude BS concentration: $14.4 \%$ ). In contrast, the growth rate of N-RM25 in TSB media containing $0.075 \%$ of BS No. 3 (estimated corresponding crude BS concentration: $0.225 \%$ ) was markedly reduced. Additionally, the growth of N-RM25 in the presence of a range of BS No.3 concentrations $(0.075 \%$ to $9.6 \%$ - estimated range of corresponding crude BS concentrations: 0.225 to $28.8 \%$ ) was more uniform and consistent when compared with FD436 and R-NM29 (Fig. 1).

\subsection{Experimental infection}

\subsection{1. $I D_{50}$}

The $\mathrm{ID}_{50}$ of mice for each strain via the intraperitoneal route was calculated to be 

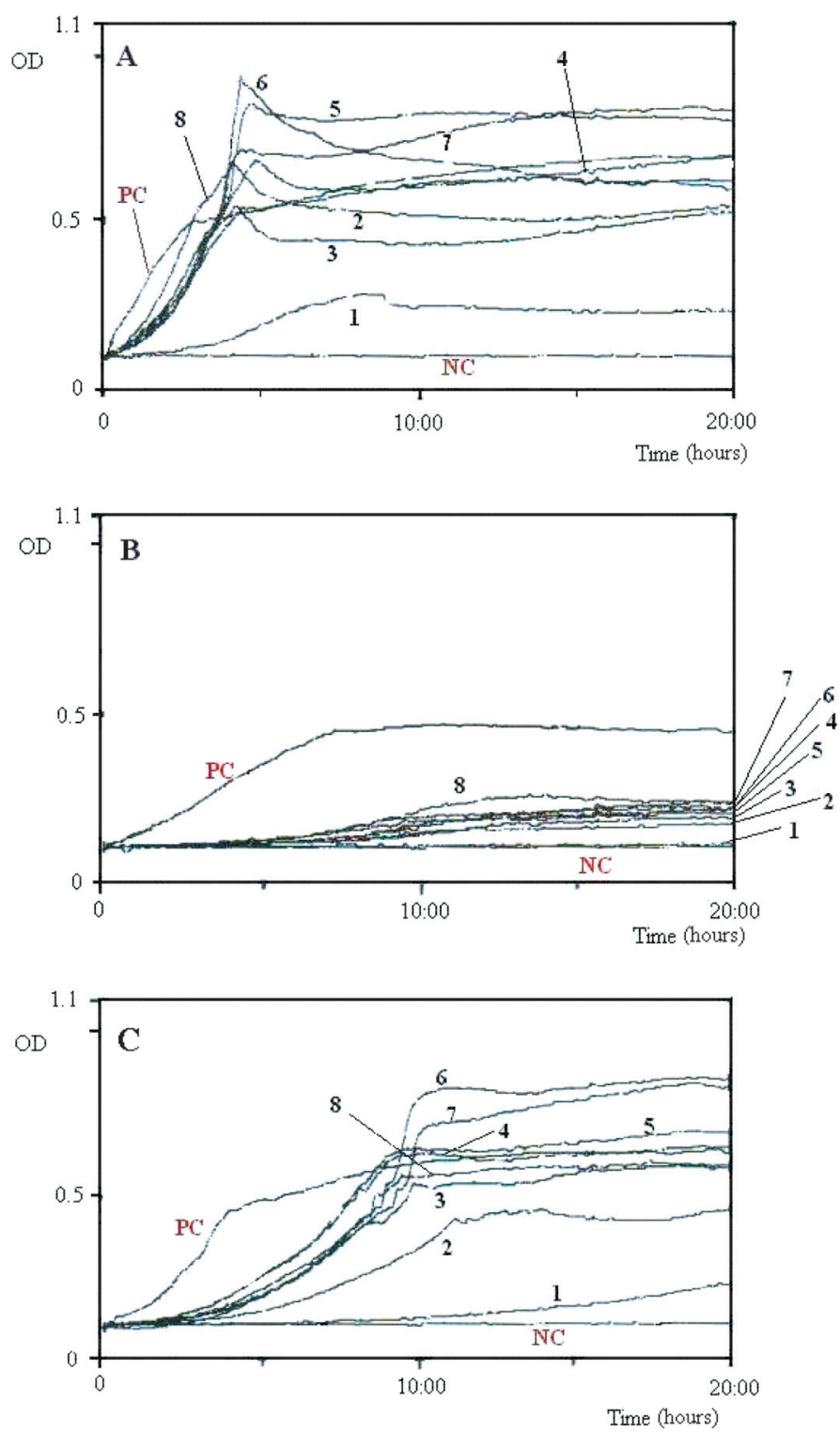

Figure 1. Growth curves of $S$. Dublin wild strain FD436 (A), metabolic-drift mutants N-RM25 (B) and R-NM29 (C) in tryptone soya broth medium containing graded concentrations of bile salts No. 3 determined using turbidimetry $\left(\mathrm{OD}_{420-580}\right)$ every $10 \mathrm{~min}$ for $20 \mathrm{~h}$. PC: positive control (the medium containing no bile salts), NC: negative control (the medium containing no bacteria), OD: optical density. The following figures indicate the concentration of bile salts No. 3 (figures in parentheses are estimated corresponding concentrations of crude bile salts). 1: $9.6 \%$ (28.8\%), 2: $4.8 \%$ (14.4\%), 3: $2.4 \%$ (7.2\%), $4: 1.2 \%$ (3.6\%), 5: $0.6 \%$ (1.8\%), 6: $0.3 \%$ (0.9\%), $7: 0.15 \%(0.45 \%), 8: 0.075 \%$ $(0.225 \%)$. 
$7.3 \times 10^{2}$ cfu for FD436, $>5.1 \times 10^{8}$ cfu for N-RM25 and $>2.7 \times 10^{8}$ cfu for R-NM29.

\subsubsection{Clinical appearance and shedding of Salmonella in faeces}

All mice inoculated with FD436 showed severe clinical signs of salmonellosis, and were euthanised or had died by Day 6 . Mice in the N-RM25 and R-NM29 inoculated groups and the control produced no clinical signs throughout the observation period, except for two mice in the R-NM29 group which were ill (they were less active than the controls) on Day 5 and then recovered. Mice in the N-RM25, RNM29 and control groups had significantly fewer clinical signs than mice in the FD436 group ( $p<0.0001, p=0.0006$, and $p=0.0046$, respectively) and showed no significant difference when compared to each other (Tab. I).

Salmonella were first isolated from the faeces of mice in the FD436 group on Day 3 P.I., and then consistently isolated using the DI method until all mice in this group were euthanised or had died. Throughout the 24-day observation period, nalidixic acid and rifampicin resistant Salmonella (confirmed to be N-RM25) were isolated from the faeces of mice in the N-RM25 group intermittently between Day 5 and Day 12, but only by using the EI method. Salmonella were not isolated from the faeces of mice in the R-NM29 and control groups during the observation period (Tab. I).

\subsubsection{Isolation of Salmonella from heart blood, gall bladder bile and liver plus spleen samples}

The challenge strain was first isolated from the heart blood of mice in all groups, except the control, on the first day following inoculation. The organisms were then continuously re-isolated from that site of FD436 inoculated mice using the DI method until all animals in this group were euthanised or had died. Nalidixic acid and rifampicin resistant Salmonella (confirmed to be N-RM25) were isolated on Day 3 P.I. from the heart blood of a mouse in the N-RM25 group using the DI method, and then isolated from another mouse in this group using the EI method on Day 7 only. Salmonella were not isolated from heart blood samples from mice inoculated with R-NM29 during the observation period except on Day 1 (Tab. II).

Quantitative culture of Salmonella from the liver plus spleen samples of the FD436 and N-RM25 treated groups was continuously achieved throughout the observation period. The number of Salmonella isolated from the organs in the FD436 group increased from approximately $10^{1}$ to $10^{7} \mathrm{cfu} / \mathrm{g}$ within 5 days P.I. In contrast, the numbers of Salmonella isolated from the organs of mice inoculated with N-RM25 between Days 1 and 7 were approximately $10^{3} \mathrm{cfu} / \mathrm{g}$. The number of organisms then remained stable between $10^{1}$ and $10^{2} \mathrm{cfu} / \mathrm{g}$ to the end of the observation period. Salmonella were not isolated from the organs of R-NM29 inoculated mice nor from the uninoculated controls (Tab. II and Fig. 2).

Salmonella were first isolated from gall bladder bile of mice in the FD436 and NRM25 groups using the DI method on Day 5 P.I. During the 24-day observation period, N-RM25 was re-isolated from mice in Group 5 by the DI method on Days 12 and 15. The organisms were also isolated on Day 21 but only using the EI method. Salmonella were not isolated from bile of mice in the R-NM29 or control group (Tab. II).

\subsubsection{Post-mortem examination}

No gross changes were evident in the organs of the mice euthanised on the 


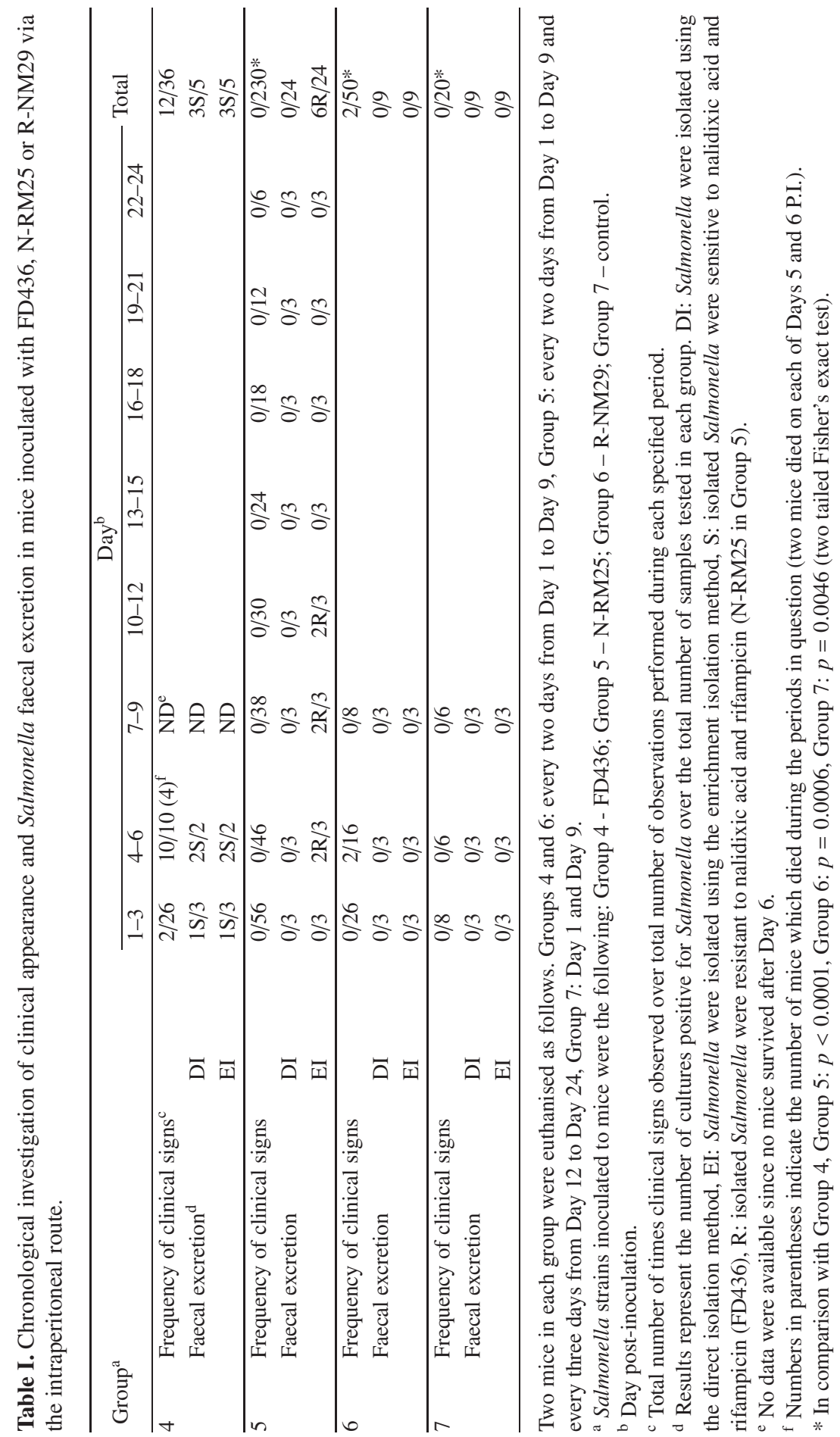


Table II. Chronological investigation of penetration by Salmonella of heart blood (HB), liver (L), spleen (S) and gall bladder bile (GBB) of mice administered FD436, N-RM25 or R-NM29 via the intraperitoneal route.

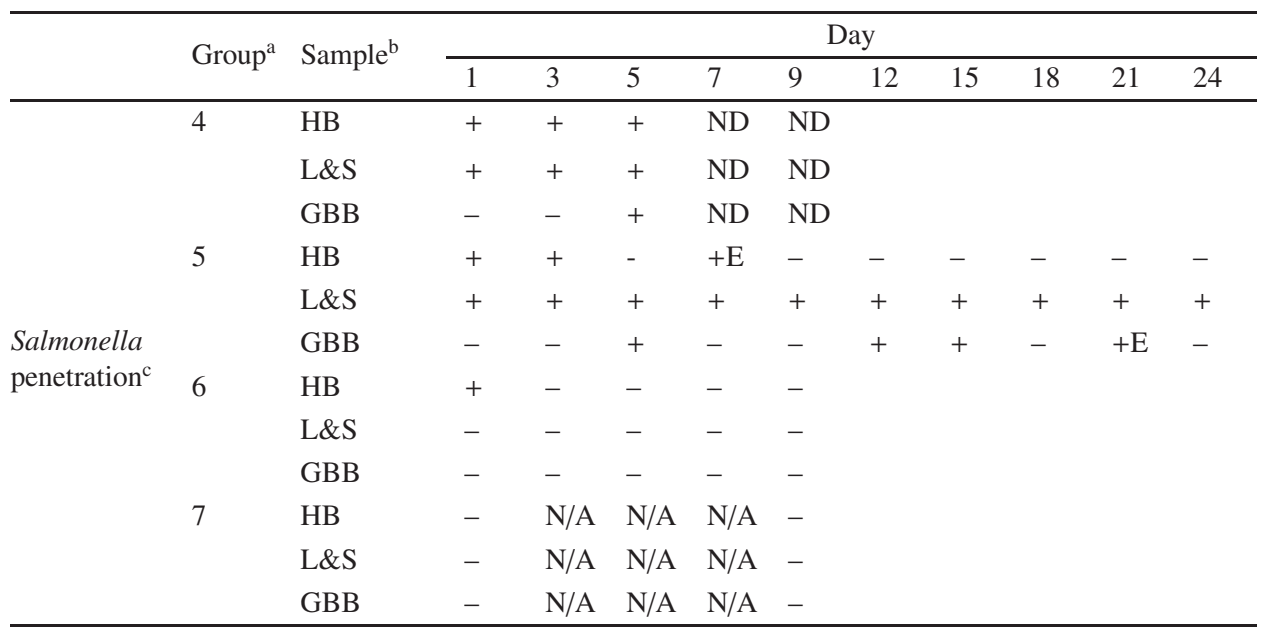

${ }^{a}$ Salmonella strains inoculated to mice were the following: Group 4 - FD436; Group 5 - N-RM25; Group 6 - R-NM29; Group 7 - control.

${ }^{\mathrm{b}}$ Samples were collected from a single animal at each time point.

${ }^{c}$ The number of viable Salmonella cells in the liver and spleen is indicated in Figure 2.

Day: day post-inoculation, +: positive for Salmonella isolation by using the direct isolation method,-: negative for Salmonella isolation, E: positive for Salmonella isolation only by using the enrichment isolation method, ND: no data available since no mice survived.

day following inoculation. In mice given FD436, scattered petechial haemorrhages were observed on the serosa of the liver in mice euthanised on Day 3 P.I. Cloudy, straw-coloured fibrinous exudate appeared on the surface of the serosa of the visceral organs and the peritoneum of mice in this group euthanised on Day 5. Splenomegaly and petechial haemorrhages on the serosa of the visceral organs (especially the liver) were also prominent in the same mice. In contrast to these findings, no gross lesions were observed upon autopsy of the mice in the N-RM25 group throughout the observation period with the exception of slight splenomegaly in some mice euthanised on Days 5, 7, 9 and 12. No gross lesions were observed in visceral organs of mice in the R-NM29 and control groups during the observation period.

\subsubsection{Histopathology of the liver, spleen and gall bladder}

The HP and BP scores of each group are shown in Table III. In the FD436 inoculated group, a few randomly scattered inflammatory foci composed of neutrophils and lymphocytes were observed in the liver on Day 1. By Days 3 to 5, diffuse sinusoidal leucocytosis was evident as were scattered foci of lytic necrosis. A variable portal neutrophilic vasculitis often with thrombosis and associated coagulative necrosis was also evident. Rod-shaped bacteria (putative Salmonella cells) were observed predominantly in Kupffer cells (Fig. 3A). By 3 days P.I., there was an increased cellularity of sinusoids within the spleen and this was marked by Day 5. Neutrophils were the predominate cell type. 


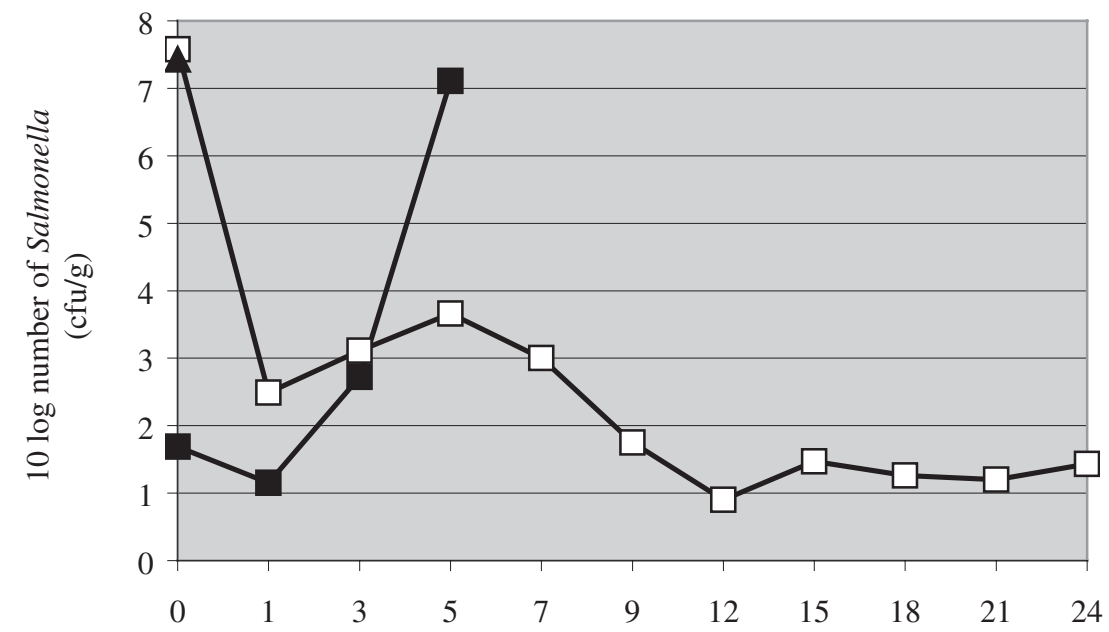

Day (post-inoculation)

Figure 2. Enumeration of Salmonella in liver plus spleen of mice P.I. with wild strain FD436 (Group 4: black square), S. Dublin metabolic-drift mutants N-RM25 (Group 5: white square) or R-NM29 (Group 6: black triangle). Samples were collected from a single animal at each time point. The numbers of Salmonella on Day 0 indicate the infectious doses of FD436, N-RM25 and R-NM29 inoculated to mice via the intraperitoneal route in each group. Mice in Group 4 were euthanised or had died by Day 6 P.I. Salmonella were not isolated from the livers and spleens of mice in Group 6 throughout the nine-day observation period.

In the gall bladder, a severe suppurative cholecystitis was evident on Day 5. This was characterised by marked epithelial hyperplasia along with a prominent transmural inflammatory infiltrate composed predominantly of neutrophils, lymphocytes and macrophages. Also apparent was variable oedema and haemorrhage along with patchy fibroplasia (Fig. 3C). On Day 5 P.I., bacteria could be seen to extend into the lumen of the gall bladder and were also apparent within the lamina propria and submucosa (Fig. 3E).

In the liver of mice inoculated with $\mathrm{N}-\mathrm{RM} 25$, a mild periportal inflammatory infiltrate as well as occasional scattered foci of suppurative inflammation were evident throughout the observation period. Prominent hepatocellular regeneration was evident after Day 7. Until Day 9 P.I., the spleen of mice in this group revealed mild lymphoid hyperplasia, patchy extramedullary haematopoiesis and also contained scattered aggregates of neutrophils. Inflammation was not evident after Day 12. Mice in this group showed a reduced rate of progression of inflammation in the gall bladder compared to mice in the FD436 group. A mild neutrophilic inflammatory infiltrate was first observed in the organ on Day 5 and this soon became moderate in degree. Also apparent was hypertrophy of mucosal epithelial cells as well as patchy oedema. These changes were observed until Day 15. No apparent inflammation was seen in the gall bladder during the remainder of the observation period (Fig. 3D). Whilst a small number of rod-shaped bacteria (putative Salmonella cells) were intermittently observed in the lumen during the 

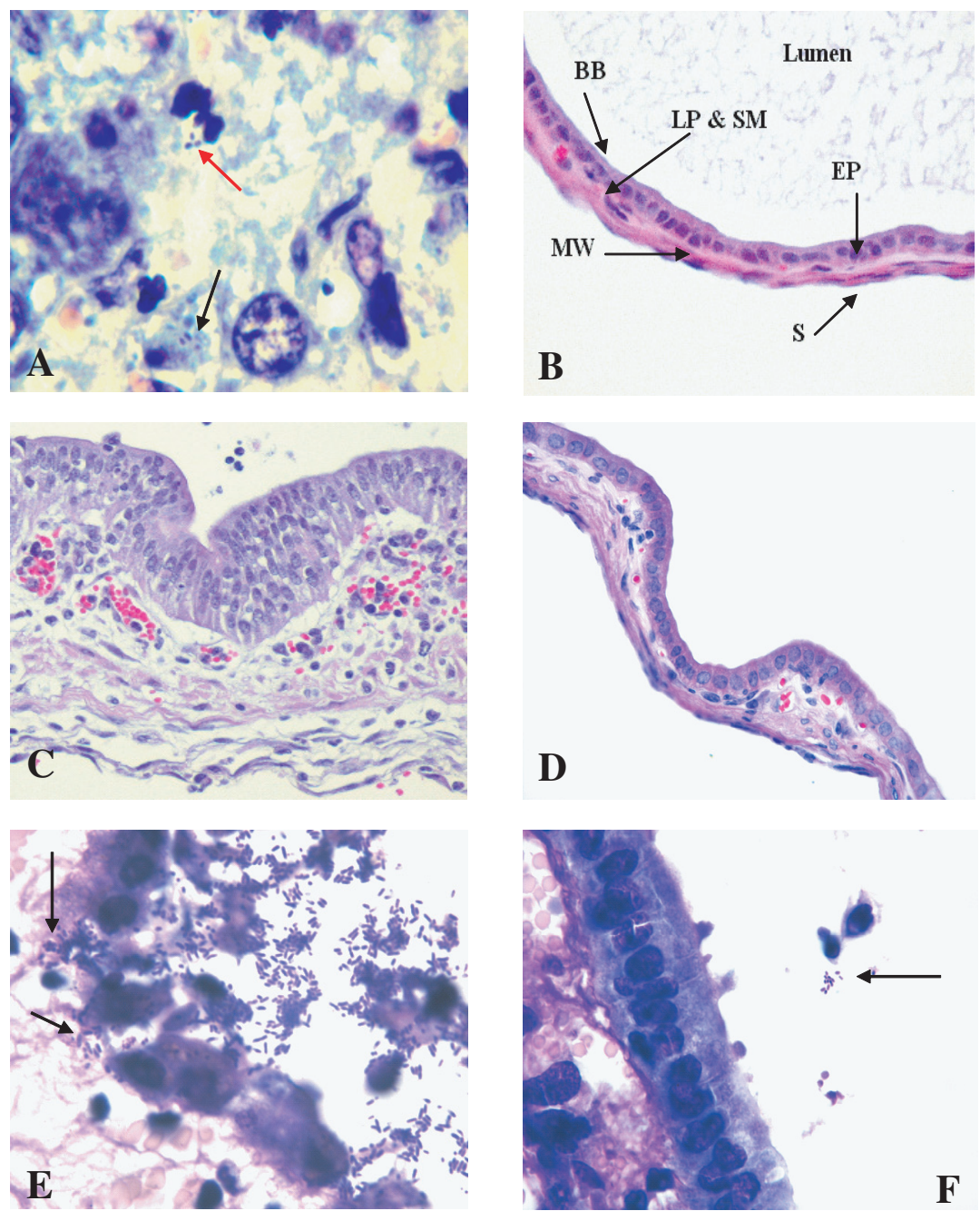

Figure 3. Pathological changes in liver (A) and gall bladder (B - F). A: Day 5 P.I. with FD436 (Group 4). Putative Salmonella cells are observed in a Kupffer cell (black arrow) and a neutrophil (red arrow). $\times 1000$, Giemsa stain. B: Gall bladder from control mouse (Group 7). BB: brush border; EP: epithelium; LP: lamina propria; SM: submucosa; MW: muscular wall; and S: serosa. $\times 400$, H\&E stain. C: Day 5 P.I. with FD436 (Group 4). Severe acute cholecystitis. Epithelial hyperplasia, with oedema, haemorrhage and fibroplasia within the lamina propria to subserosa. Neutrophils are the predominant infiltrating inflammatory cell. $\times 400, \mathrm{H} \& \mathrm{E}$ stain. D: Mouse euthanised on Day 18 P.I. with N-RM25 (Group 5). Inflammation is not evident except very mild infiltration of mononuclear cells with oedema of LP and SM. $\times 400$, H\&E stain. E: Day 5 P.I. with FD436. A large number of organisms is present in the lumen and mucosa (arrows). Exfoliation of epithelium and large numbers of neutrophils are evident. $\times 1000$, Giemsa stain. F: Day 5 P.I. with N-RM25. Organisms are present in the lumen in low numbers (arrow). Epithelium maintains monolayer. $\times 1000$, Giemsa stain. 
Table III. Chronological investigation of histopathological (HP) and bacterial penetration (BP) scores from liver (L), spleen (S) and gall bladder (GB) of mice administered FD436, N-RM25 or R-NM29 via the intraperitoneal route.

\begin{tabular}{|c|c|c|c|c|c|c|c|c|c|c|c|c|}
\hline & \multirow{2}{*}{ Group $^{a}$} & \multirow{2}{*}{ Sample } & \multicolumn{10}{|c|}{ Day } \\
\hline & & & 1 & 3 & 5 & 7 & 9 & 12 & 15 & 18 & 21 & 24 \\
\hline \multirow{12}{*}{ HP score } & \multirow[t]{3}{*}{4} & $\mathrm{~L}$ & 1 & 3 & 3 & ND & ND & & & & & \\
\hline & & S & 0 & 2 & 3 & ND & ND & & & & & \\
\hline & & GB & 0 & 1 & 3 & ND & ND & & & & & \\
\hline & \multirow[t]{3}{*}{5} & $\mathrm{~L}$ & 0 & 1 & 2 & 2 & 2 & 1 & 1 & 1 & 1 & 1 \\
\hline & & S & 0 & 0 & 2 & 1 & 1 & 0 & 0 & 0 & 0 & 0 \\
\hline & & GB & 0 & 0 & 1 & 0 & 0 & 2 & 2 & 0 & 1 & 0 \\
\hline & \multirow[t]{3}{*}{6} & $\mathrm{~L}$ & 0 & 1 & 1 & 1 & 0 & & & & & \\
\hline & & S & 0 & 0 & 1 & 1 & 0 & & & & & \\
\hline & & GB & 0 & 0 & 0 & 0 & 0 & & & & & \\
\hline & \multirow[t]{3}{*}{7} & $\mathrm{~L}$ & 0 & N/A & N/A & N/A & 0 & & & & & \\
\hline & & S & 0 & $\mathrm{~N} / \mathrm{A}$ & N/A & $\mathrm{N} / \mathrm{A}$ & 0 & & & & & \\
\hline & & GB & 0 & $\mathrm{~N} / \mathrm{A}$ & N/A & $\mathrm{N} / \mathrm{A}$ & 0 & & & & & \\
\hline \multirow{4}{*}{ BP score } & 4 & GB & 0 & 0 & 3 & ND & ND & & & & & \\
\hline & 5 & GB & 0 & 0 & 1 & 0 & 0 & 1 & 1 & 0 & 1 & 0 \\
\hline & 6 & GB & 0 & 0 & 0 & 0 & 0 & & & & & \\
\hline & 7 & GB & 0 & N/A & $\mathrm{N} / \mathrm{A}$ & $\mathrm{N} / \mathrm{A}$ & 0 & & & & & \\
\hline
\end{tabular}

a Salmonella strains inoculated to mice were the following: Group 4 - FD436; Group 5 - N-RM25; Group 6 - R-NM29; Group 7 - control.

Day: day post-inoculation, ND: no data available since no mice survived.

HP score: $0=$ no detectable pathological change, $1=$ mild changes, $2=$ moderate changes, $3=$ marked changes.

BP score: $0=$ no detectable penetration, $1=$ penetration of the lumen only, $2=$ penetration of the lumen and mucosa, 3 = penetration of the lumen, mucosa and submucosa.

observation period, penetration to the mucosa or the deeper layers by the organism was not evident (Fig. 3F).

In the liver of mice in the R-NM29 group, a mild periportal inflammatory infiltrate of neutrophils was seen on Days 3, 5 and 7. Occasional suppurative foci composed of neutrophils and lymphocytes were also evident on Days 5 and 7. Mild lymphoid hyperplasia and extramedullary haematopoiesis were evident in the spleen of mice in this group on Days 5 and 7 . No apparent inflammation was observed in these organs on Day 9. No pathological changes were ever seen in the gall bladder of mice in this group.

Pathological changes were not evident in the liver, spleen and gall bladder in the control group.

\subsection{Immunological assays}

An increase in the mean titre of serum IgG in mice vaccinated with N-RM25 was observed 7 days P.I. The mean titres in this group on Days 14 and 21 were significantly higher than in the control group on the same days $(p<0.01)$. While the mean titre 
of $\mathrm{IgG}$ in the R-NM29 vaccinated mice increased significantly more than that of the control mice $(p<0.01)$ during the same period, the titres in this group on Days 14 and 21 were significantly lower than in mice given N-RM25 (Day 14: $p<0.05$, Day 21: $p<0.01$ ) (Fig. 4A).

The mean serum IgA titres of mice in the vaccinated groups also started to increase 7 days P.I. Mice in the N-RM25 vaccinated group produced significant titres on Days 14 and 21 when compared with the control group (Day 14: $p<0.05$, Day 21: $p<0.01)$. Mice vaccinated with $\mathrm{R}$ NM29 also produced increased serum IgA titres on Days 14 and 21. However, the mean titre of this group on Day 21 was significantly lower than that of the N-RM25 group ( $p<0.01)$ (Fig. 4B).

Mice administered with N-RM25 also produced significant titres of secretory IgA on Days 14 and 21 when compared with mice in both the R-NM29 and control groups (Day 14: $p<0.01$, Day 21: $p<0.05)$ (Fig. 4C).

\subsection{Vaccine trials with $\mathrm{N}-\mathrm{RM} 25$ and R-NM29}

\subsubsection{Clinical appearance and Salmonella shedding in faeces}

Following challenge infection, there were significant differences in the number of surviving mice between the N-RM25 vaccine and control groups ( $p=0.0079)$. Mice in the N-RM25 vaccine group remained healthy and survived throughout the observation period. Four out of eight mice vaccinated with R-NM29 were euthanised due to severe clinical signs of salmonellosis between Day 7 and Day 12 post-challenge (P.C.). Whilst some of the remaining mice in this group were moderately ill between Days 5 and 13 P.C., no more mice were euthanised. All mice in
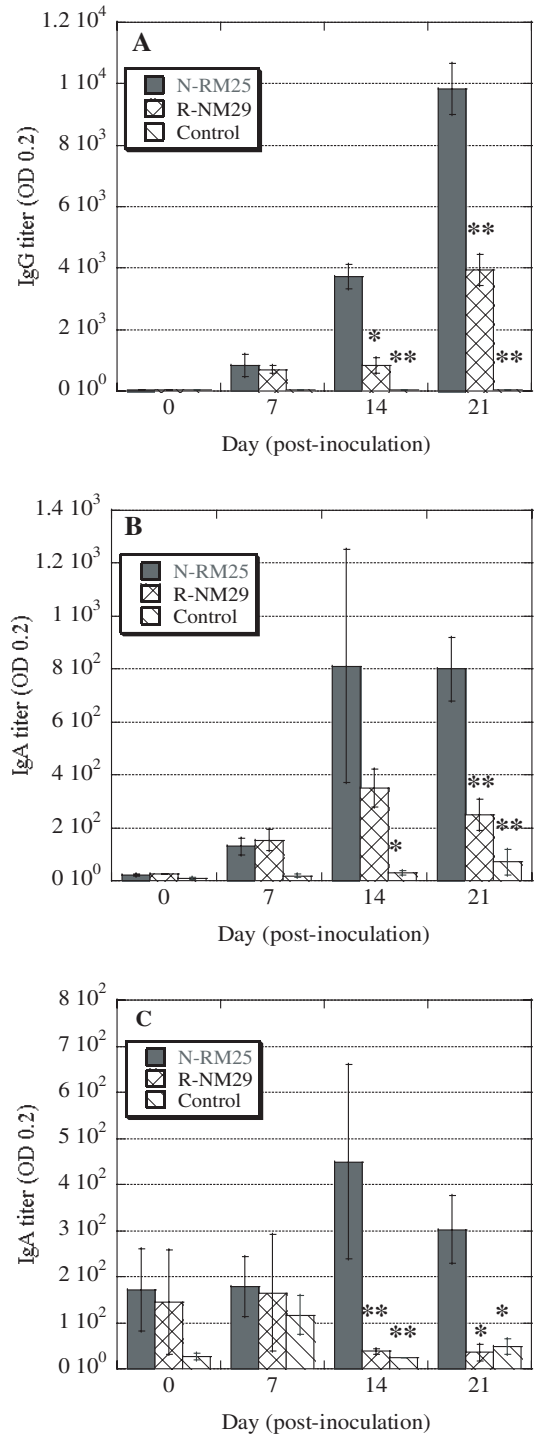

Figure 4. Mean titres of serum $\operatorname{IgG}(\mathrm{A})$ and $\operatorname{Ig} \mathrm{A}$ (B), and intestinal secretory $\operatorname{IgA}(\mathrm{C})$ in mice measured using ELISA following administration with N-RM25 or R-NM29 via the intraperitoneal route. Grey bars - Group 8 (mice administered with N-RM25); cross-hatched bars - Group 9 (mice administered with R-NM29), and; hatched bars - Group 10 (control) $(n=5$ /group/time). Error bars represent \pm of SEM. $* p<0.05$ and $* * p<0.01$ (two-tailed MannWhitney test) when compared with Group 8 . 


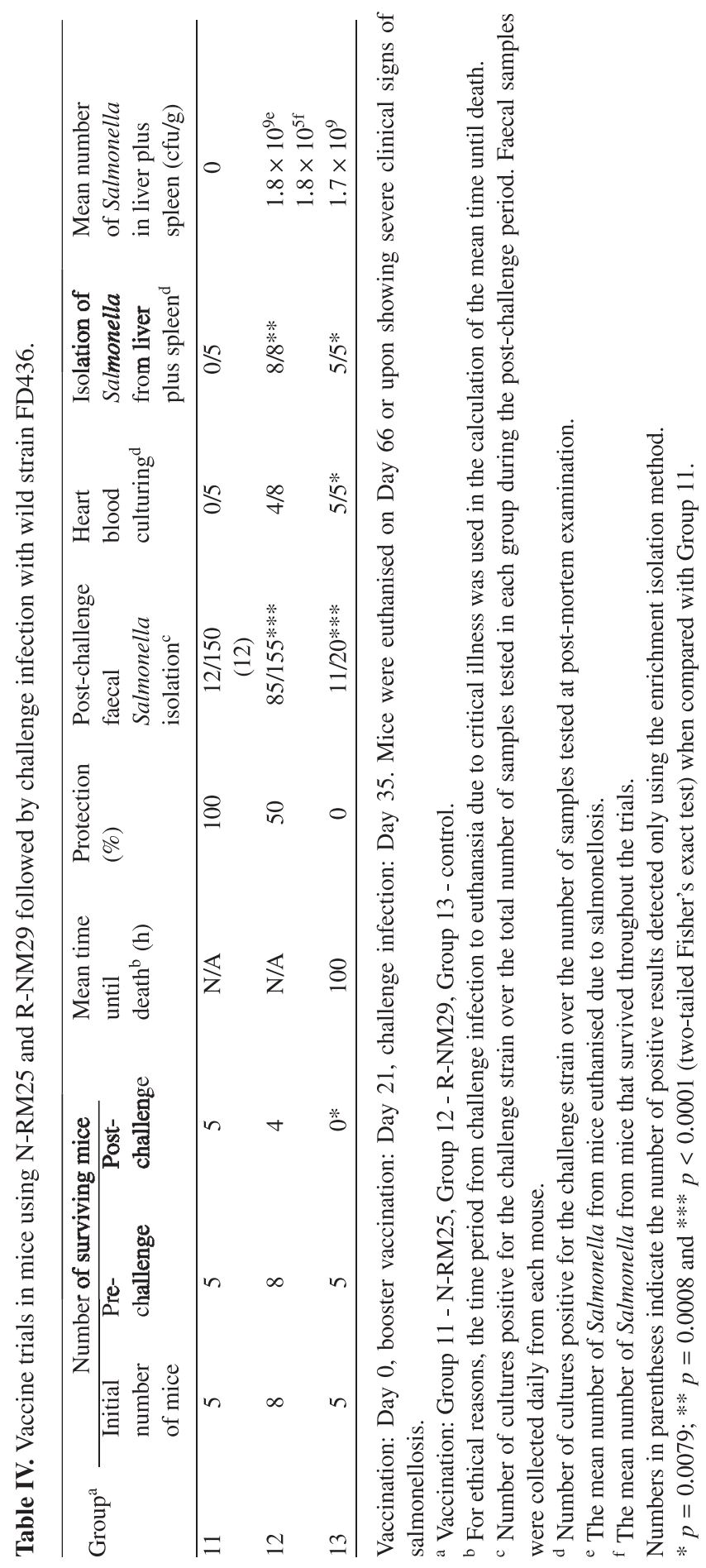


the unvaccinated control group were euthanised due to salmonellosis by 4 days P.C. (Tab. IV).

The N-RM25 vaccine strain was isolated from the faeces of some mice in Group 11 during the pre-challenge period. However, isolation was intermittent and only for short periods ( $\leqslant 7$ days) following each vaccination, and was only possible using the EI method. Mice in the R-NM29 vaccinated and control groups did not shed Salmonella in their faeces during the same period. Following challenge infection, mice vaccinated with N-RM25 excreted Salmonella in their faeces significantly less frequently than mice in the other groups $(p<0.0001)$. The challenge strain (FD436) was occasionally isolated using the EI method from the faeces of only two mice receiving the N-RM25 vaccine. The challenge strain was isolated from all mice in the R-NM29 vaccinated group using the DI method almost everyday from Day 3 P.C. to the end of the observation period. In the control group, the challenge strain was continuously isolated from the day following challenge to the day by which all mice were euthanised (Tab. IV).

\subsubsection{Post-mortem examination}

No gross lesions were observed at postmortem in any of the mice vaccinated with $\mathrm{N}-\mathrm{RM} 25$. The surviving mice in the RNM29 vaccine group showed mild to moderate pathological changes, such as mild splenomegaly and pale foci on the surface of the liver. The four mice in this group and all mice in the control group euthanised due to salmonellosis developed severe splenomegaly and petechial haemorrhages of the serosa of visceral organs. Two of these euthanised mice had marked fibrinous exudate in the abdominal cavity and small grey-white foci scattered across the entire surface of the liver.

\subsubsection{Isolation of Salmonella from heart blood, liver plus spleen and other major organs}

No Salmonella were isolated even using the EI method from the heart blood of any mouse receiving the N-RM25 vaccine or the surviving mice vaccinated with R-NM29. In contrast, the challenge strain was isolated from this site in all mice euthanised due to salmonellosis. Frequency of Salmonella isolation from the heart blood between mice in the N-RM25 group and the control was significantly different $(p=0.0079)$ (Tab. IV).

There were also significant differences in the penetration of the liver and spleen by Salmonella between the N-RM25 group and the other groups (R-NM29: $p=$ 0.0008, control: $p=0.0079$ ). The organisms were not isolated from the liver and spleen of any mouse vaccinated with N-RM25. In contrast, the challenge strain was isolated in large numbers $\left(1.1 \times 10^{9}\right.$ to $2.4 \times 10^{9} \mathrm{cfu} / \mathrm{g}$ ) from these organs of four mice in the R-NM29 vaccine group that were euthanised due to salmonellosis, and in smaller numbers from those surviving to the end of the experiment. The challenge strain was present $\left(5.3 \times 10^{8}\right.$ to $\left.3.3 \times 10^{9} \mathrm{cfu} / \mathrm{g}\right)$ in the organs of all control mice (Tab. IV).

The challenge strain was isolated only from the ileocaecum of one of the five mice vaccinated with $\mathrm{N}-\mathrm{RM} 25$ using the EI method. The N-RM25 vaccine strain was also isolated following enrichment from the ileocaecum and colon of one out of five mice in this group. In addition to the liver and spleen, the challenge strain was isolated from a variety of other organ sites (ileocaecum, caecum, colon and kidney) of mice in the R-NM29 group (Tab. V).

\section{DISCUSSION}

Metabolic-drift mutants created by generation of spontaneous chromosomal 
Table IV. Distribution of Salmonella in intestinal organs of mice that survived throughout vaccine trials using N-RM25 and R-NM29 followed by challenge infection with wild strain FD436.

\begin{tabular}{lcccccccc}
\hline Group $^{\mathrm{a}}$ & \multicolumn{8}{c}{ Organ } \\
\cline { 2 - 9 } & Lung & $\begin{array}{c}\text { Liver and } \\
\text { spleen }\end{array}$ & $\begin{array}{c}\text { Duodenum } \\
\text { and jejunum }\end{array}$ & Ileum & Ileocaecum & Caecum & Colon & Kidney \\
\hline $11(n=5)$ & $0 / 5$ & $0 / 5$ & $0 / 5$ & $0 / 5$ & $1 \mathrm{~S}, 1 \mathrm{R} / 5(2)$ & $0 / 5$ & $1 \mathrm{R} / 5(1)$ & $0 / 5$ \\
$12(n=4)$ & $0 / 4$ & $4 \mathrm{~S} / 4$ & $0 / 4$ & $0 / 4$ & $3 \mathrm{~S} / 4$ & $3 \mathrm{~S} / 4$ & $2 \mathrm{~S} / 4$ & $1 \mathrm{~S} / 4$ \\
\hline
\end{tabular}

a Vaccination: Group 11 - N-RM25, Group 12 - R-NM29.

Results represent the numbers of cultures positive for the corresponding vaccine strains and the challenge strain over the total number of samples tested in each group. S: nalidixic acid and rifampicin sensitive (challenge) strain, R: nalidixic acid and rifampicin resistant (vaccine) strains. Numbers in parentheses indicate the number of isolates obtained using the enrichment isolation method.

mutations in FD436 were selected for this study because the use of genetically modified organisms as veterinary live vaccines is not permitted in Europe and has become tightly restricted elsewhere due to public health concerns [38].

The data presented clearly indicate that the $S$. Dublin metabolic drift mutant NRM25 is a highly effective live vaccine in the mouse model. In contrast, the companion mutant, R-NM29, whilst exhibiting some desirable properties, was not sufficiently protective. N-RM25 showed no cross resistance to the antimicrobials tested, and its very low reversion rate (calculated to be between $2.6 \times 10^{-20}$ and $1.8 \times 10^{-22}$ ) satisfied two essential safety criteria for use as a live attenuated vaccine. The reversion rate may indeed be lower because phenotypic differences from the parent strain suggest the presence of further chromosomal mutations in N-RM $25^{1}$.

$S$. Dublin can resist the bactericidal action of bile [36]. However, metabolicdrift mutations may affect the genes responsible for mechanisms of Salmonella bile resistance, such as multi-drug efflux pumps [33] and/or lipopolysaccharide biosynthesis [41], altering the sensitivity of the organism to bile and consequently re-

\footnotetext{
${ }^{1}$ Mizuno T., The development of a live attenuated Salmonella Dublin vaccine, Ph.D. thesis, St. Lucia, QLD, Australia, 2003.
}

ducing the growth of the mutants in the presence of this substance. The MIC and MBC of bile have confirmed that wild strain FD436 and vaccine candidates NRM25 and R-NM29 were highly resistant to bile. This suggests that they can survive in sites such as the gall bladder, thereby evading host defences because bile inactivates complement activity and lyses leukocytes [16]. In addition, because of the toxicity of bile for most Gram-positive and non bile-tolerant Gram-negative bacteria, these strains may avoid competition with other microorganisms in sites where inhibitory concentrations of bile are present. The growth of N-RM25, however, was markedly reduced, even in the presence of a very low concentration of BS No. 3 when compared with the other strains. Despite this slow growth rate, there was very little difference in the MIC and no difference in MBC of BS No. 3 for NRM25 and the wild strain. Furthermore, N-RM25 produced a much more consistent pattern of growth than did the other strains in the presence of a broad range of BS No. 3 concentrations. If N-RM25 maintains this sensitivity to bile in vivo, given that the concentration of BS in bile in the human liver $^{2}$ is approximately $1.1 \%$ and the concentration of BS in bile in the gall

\footnotetext{
${ }^{2}$ Data for mouse organs could not be found.
} 
bladder is even higher [13], the above results suggest that when N-RM25 reaches these sites, it could survive and multiply at rates markedly lower but more stable than the other strains. In addition, the reduced growth rate of the strain in the presence of bile may minimise the risk of it being excreted in the faeces in large numbers ${ }^{3}$.

The virulence study showed that both N-RM25 and R-NM29 were highly attenuated compared to FD436. N-RM25, in particular, did not induce any clinical symptoms in the experimental infection study, even though a greater number of mice in this group were tested than in the other groups. Additionally, mice given N-RM25 excreted Salmonella intermittently and for only a limited period ( $\leqslant 7$ days), with the organism detectable only following the EI method, in marked contrast to mice given FD436. This suggests that only a small number of organisms were present in the faeces, and/or the organisms in the faeces were of limited viability. Therefore, $\mathrm{N}$ RM25 may have difficulty surviving when shed in the environment, a desirable characteristic for a vaccine strain from a public health perspective.

Histopathological changes in the liver, spleen and gall bladder examined chronologically were much milder in the N-RM25 inoculated mice compared with mice given FD436. These findings were also clearly reflected in the organ culture results. The number of Salmonella in the liver plus spleen specimens from mice given FD436 increased sharply and the mice deteriorated rapidly. In contrast, although the infectious dose of N-RM25 was approximately $10^{6}$ times greater than that of FD436, the

\footnotetext{
${ }^{3}$ Linde K., Stable, highly immunogenic mutants of Salmonella with two independent, attenuating markers as potential live vaccine and their validity for Shigella and other bacteria, Proc. Int. symposium on enteric infections in man and animals: standardization of immunological procedures, Dublin, 1982, pp. 15-28.
}

number of Salmonella isolated from these organs in this group decreased to a very low level. However, N-RM25 temporarily colonised the organs and survived in small numbers throughout the twenty-four day observation period without causing disease. In separate studies, this period of colonisation was confirmed to be no longer than 52 days $^{4}$. Even though mild pathological changes were observed in the organs of mice given N-RM25, no mice in this group showed clinical signs.

Bacteriological and histopathological investigation confirmed that R-NM29 was rapidly eliminated from heart blood and was not isolated from the liver, spleen or gall bladder. As with the wild strain, NRM25 was isolated from each of these sites. On histopathology of N-RM25 infected mice, a small number of Salmonella cells were observed only in the gall bladder lumen. In contrast, FD436 penetrated the lumen, mucosa and submucosa in large numbers resulting in marked inflammation. Whilst $S$. Dublin is inherently capable of growth in the biliary system, the growth of and penetration by N-RM25 was restricted, and this may contribute in part to its lower pathogenicity. Furthermore, based on the histopathological observation of the gall bladder, a high proportion of bacterial cells in the lumen were extracellular (Figs. 3E and $3 \mathrm{~F}$ ). This suggests that, in contrast to Salmonella in the intracellular phase, extracellular N-RM25 cells are directly exposed to bile. Although some features of $\mathrm{N}-\mathrm{RM} 25$, such as slow in vitro growth rate in a nutrient medium and reduced motility, may affect its virulence, the unique sensitivity to bile may be a key characteristic to regulate the growth of N-RM25 at this site and may be an important factor contributing to attenuation. If so, the high level of attenuation of this strain might be maintained even in immuno-compromised animals, because bile would restrict the

\footnotetext{
${ }^{4}$ Mizuno T., unpublished data.
} 
growth of the strain independently of the immune response. It is also highly likely that the organism was transported in bile to the gut via the enterohepatic circulation of bile because N-RM25 was isolated from the faeces and bile at similar time points. In the chronological study following experimental infection, organ and tissue specimens were collected at set time points from different animals on each occasion. Although animals in the same genetic line and of the same age and sex were used, variations in infectivity and immunity may have occurred [4]. In spite of this, differences in the level of tissue penetration and pathological effects between N-RM25 and the wild strain were marked and uniform within all groups. Based on these results, N-RM25 appears to have many characteristics of the ideal vaccine for enabling the slow "drip feeding" stimulation principle.

Mice in the N-RM25 group produced significantly higher levels of systemic immunity (serum $\operatorname{IgG}$ and $\operatorname{IgA}$ ) against the challenge strain than mice in the R-NM29 and uninoculated control groups. One important contributor to this result is probably the ability of N-RM25 to survive in the liver and spleen in low numbers for longer than 24 days P.I. In mice, more than $99 \%$ of $\operatorname{IgA}$ produced in the intestinal mucosa is secreted into the intestinal lumen directly through epithelial cells [34]. Therefore, the results of secretory IgA titres closely reflect the actual level of immune induction at the mucosal site. Even following parenteral administration, N-RM25 also induced a significant level of mucosal immunity in the intestine. While R-NM29 produced significantly less serum humoral immunity than did N-RM25, the level was still significant when compared with the control, suggesting R-NM29 retains a certain level of immunogenicity. However, it induced no mucosal immunity. This is most likely because, unlike N-RM25, RNM29 did not reach the gut to stimulate the GALT directly. These results strongly sug- gest that the application of the slow "drip feeding" principle can enable a parenteral live vaccine to efficiently induce mucosal immunity as well as systemic immunity. If so, administration of the N-RM 25 vaccine is no longer restricted to an oral route in order to induce an efficient mucosal immune response.

The vaccine trials showed that N-RM25 possesses significant protective properties against homologous challenge infection. In the trials, since the challenge strain was given via the intraperitoneal route, it was difficult to evaluate the importance of mucosal immunity in preventing $S$. Dublin infection. However, the results obtained suggest that the challenge strain was effectively eliminated from the internal organs and intestinal lumen of mice given $\mathrm{N}-\mathrm{RM} 25$ vaccine, and that the vaccine prevented the development of systemic infection.

It can be concluded that N-RM25, which was selected using criteria developed for the slow "drip feeding" concept, is a promising live attenuated vaccine candidate for $S$. Dublin infection in cattle and the results of vaccine trials in mice must now be confirmed in the natural host. The slow "drip feeding" concept is a new approach to developing live attenuated vaccines which may be applicable to the development of vaccines for other infectious organisms in both monogastric animals and ruminants. It may also be applicable for developing other organisms to be used as vaccines and/or vectors to carry foreign antigens when oral administration is problematic but it remains desirable for the organisms to reach immune stimulation sites at mucosal surfaces in the gut.

\section{ACKNOWLEDGEMENTS}

This work was supported by grants from Australian Commonwealth Biotechnology Innovation Funding (No. BIF03317); The University of Queensland and HerdVac Pty. 
Ltd. We are indebted to the Ruminant Immunology Research Group, Australian Animal Health Laboratory, Commonwealth Scientific and Industrial Research Organization, Australia, for assistance with ELISA.

\section{REFERENCES}

[1] Anderson M., Blanchard P., The clinical syndromes caused by Salmonella infection, Vet. Med. (1989) 84:816-819.

[2] Bowersock T.L., Shalaby W.S.W., Levy M., Blevins W.E., White M.R., Borie D.L., Park K., The potential use of poly (methacrylic acid) hydrogels for oral administration of drugs and vaccines to ruminants, J. Control. Release (1994) 31:245-254.

[3] Bowersock T.L., HogenEsch H., Suckow M., Guimond P., Martin S., Borie D., Torregrosa S., Park H., Park K., Oral vaccination of animals with antigens encapsulated in alginate microspheres, Vaccine (1999) 17:18041811.

[4] Boyce J.D., Wilkie I., Harper M., Paustian M.L., Kapur V., Adler B., Genomic scale analysis of Pasteurella multocida gene expression during growth within the natural chicken host, Infect. Immun. (2002) 70:6871-6879.

[5] Bridson E.Y., The Oxoid Manual, Oxoid, Hampshire, 1998, pp. 3:16-17.

[6] Carlton B.C., Brown B.J., Gene Mutation, in: Gerhardt P., Murray R.G., Costilow R.N., Nester E.W., Wood M.W., Krieg N.R., Phillips G.B. (Eds.), Manual of Methods for General Bacteriology, American Society for Microbiology, Washington, DC, 1981, pp. 232-234.

[7] Chambers P.G., Lysons R.J., The inhibitory effect of bovine rumen fluid on Salmonella typhimurium, Res. Vet. Sci. (1979) 26:273276.

[8] Cox E., Verdonck F., Vanrompay D., Goddeeris B., Adjuvants modulating mucosal immune responses or directing systemic responses towards the mucosa, Vet. Res. (2006) 37:511-539.

[9] DesBordes C.K., Welch J.G., Influence of specific gravity on rumination and passage of indigestible particles, J. Anim. Sci. (1984) 59:470-475.

[10] Ferraro M.J., Craig W.A., Eliopoulos G., Fung-Tomc J., Hansen S.L., Hecht D.W., Hindler J., Reller L.B., Sahm D.F., Swenson
J.M., Tenover F.C., Testa R.T., Wilker M.A., Performance standards for antimicrobial susceptibility testing; Eighth Informational Supplement, NCCLS (1998) 18:1-35.

[11] Gerdts V., Mutwiri G.K., Tikoo S.K., Babiuk L.A., Mucosal delivery of vaccines in domestic animals, Vet. Res. (2006) 37:487510.

[12] Griggs D.J., Gensberg K., Piddock L.J.V., Mutations in gyrA gene of quinoloneresistant Salmonella serotypes isolated from humans and animals, Antimicrob. Agents Chemother. (1996) 40:1009-1013.

[13] Guyton A.C., Hall J.E., Textbook of medical physiology, Elsevier Saunders, Pennsylvania, 2006, pp. 802-807.

[14] Hinton M., Salmonella dublin abortion in cattle: studies on the clinical aspects of the condition, Br. Vet. J. (1974) 130:556-562.

[15] Jin D.J., Gross C.A., Mapping and sequencing of mutations in the Escherichia coli rpoB gene that lead to rifampicin resistance, J. Mol. Biol. (1988) 202:45-58.

[16] Kaye D., Palmieri M., Rocha H., Effect of bile on the action of blood against Salmonella, J. Bacteriol. (1966) 91:945-952.

[17] Kodama C., Eguchi M., Sekiya Y., Yamamoto T., Kikuchi Y., Matsui H., Evaluation of the Lon-deficient Salmonella strain as an oral vaccine candidate, Microbiol. Immunol. (2005) 49:10351045.

[18] Levine M.M., Dougan G., Optimism over vaccines administered through mucosal surfaces, Lancet (1998) 351:1375-1376.

[19] Linde K., Beer J., Bondarenko V., Stable Salmonella live vaccine strains with two or more attenuating mutations and any desired level of attenuation, Vaccine (1990) 8:278282.

[20] Mastroeni P., Cahill B., Simmons C., Dougan G., Vaccines against gut pathogens, Gut (1999) 45:633-635.

[21] Matsui H., Suzuki M., Isshiki Y., Kodama C., Eguchi M., Kikuchi Y., Motokawa K., Takaya A., Tomoyasu Y., Yamamoto T., Oral immunization with ATP-dependent proteasedeficient mutants protects mice against subsequent oral challenge with virulent Salmonella enterica serovar Typhimurium, Infect. Immun. (2003) 71:30-39.

[22] McClelland M., Sanderson K.E., Spieth J., Clifton S.W., Latreille P., Courtney L., Porwollik S., Ali J., Dante M., Du F., Hou S., Layman D., Leonard S., Nguyen C., Scott K., 
Holmes A., Grewal N., Mulvaney E., Ryan E., Sun H., Florea L., Miller W., Stoneking T., Nhan M., Waterston R., Wilson R.K., Complete genome sequence of Salmonella enterica serovar Typhimurium LT2, Nature (2001) 413:852-856.

[23] Miles A.A., Misra S.S., Irwin J.O., The estimation of the bactericidal power of the blood, J. Hyg. Camb. (1938) 38:732-749.

[24] Oram M., Fisher M., 4-quinolone resistance mutations in the DNA gyrase of Escherichia coli clinical isolates identified by using the polymerase chain reaction, Antimicrob. Agents Chemother. (1991) 35:387-389.

[25] Quinn P.J., Carter M.E., Markey B.K., Carter G.R., Clinical Veterinary Microbiology, Mosby International, Philadelphia, 1999, pp. 226-236.

[26] Reed L.J., Muench H., A simple method of estimating fifty per cent endpoints, Am. J. Hyg. (1937) 27:493-497.

[27] Richardson A., Salmonella dublin infection in cattle, Aust. Vet. J. (1974) 50:463-466.

[28] Segall T., Lindberg A.A., Oral vaccination of calves with an aromatic-dependent Salmonella dublin $(\mathrm{O} 9,12)$ hybrid expressing $\mathrm{O} 4,12$ protects against $S$. dublin $(\mathrm{O} 9,12)$ but not against Salmonella typhimurium (O4, 5, 12), Infect. Immun. (1993) 61:1222-1231.

[29] Smith B.P., Reina-Guerra M., Hoiseth S., Stocker B.A., Habasha F., Johnson E., Merritt F.F., Aromatic-dependent Salmonella typhimurium as modified live vaccines for calves, Am. J. Vet. Res. (1984) 45:59-66.

[30] Smith B.P., Reina-Guerra M., Stocker B.A., Hoiseth S., Johnson E.H., Vaccination of calves against Salmonella dublin with aromatic-dependent Salmonella typhimurium, Am. J. Vet. Res. (1984) 45:1858-1861.

[31] Smith B.P., Salmonellosis, in: Reinhardt R.W. (Ed.), Large animal internal medicine, C.V. Mosby, St. Louis, 1990, pp. 818-822.

[32] Smith B.P., Dilling G.W., Roden L.D., Stocker B.A., Vaccination of calves with orally administered aromatic-dependent Salmonella dublin, Am. J. Vet. Res. (1993) 54:1249-1255.
[33] Thanassi D.G., Cheng L.W., Nikaido H., Active efflux of bile salts by Escherichia coli, J. Bacteriol. (1997) 179:2512-2518.

[34] Tizard I.R., Immunology, Saunders College Publishing, Philadelphia, 1995, pp. 347-358.

[35] Uren T., Wijburg O.L.C., Simmons C., Johansen F., Brandtzaeg P., Strugnell R., Vaccine-induced protection against gastrointestinal bacterial infections in the absence of secretory antibodies, Eur. J. Immunol. (2005) 35:180-188.

[36] Van Velkinburgh J.C., Gunn J.S., PhoPPhoQ-regulated loci are required for enhanced bile resistance in Salmonella spp., Infect. Immun. (1999) 67:1614-1622.

[37] Watts J.L., Chengappa M.M., Cole J.R., Cooper J.M., Hoffman L.J., Inzana T.J., Owens W.E., Shryock T.R., Thornsberry C., Walker R.D., Performance standards for antimicrobial disk and dilution susceptibility tests for bacteria isolated from animals; tentative standard, NCCLS (1997) 17:1-63.

[38] World Organization for Animal Health, Manual of diagnostic tests and vaccines for terrestrial animals, OIE, Paris, 2004, pp. 1018-1032.

[39] Wray C., McLaren I., Further studies on the use of Gal E mutants of Salmonella typhimurium in calves: oral vaccination and toxicity studies, J. Vet. Med. B (1987) 34:22-29.

[40] Wray C., Davies R.H., Salmonella infections in cattle, in: Wray C., Wray A. (Eds.), Salmonella in domestic animals, CABI Publishing, New York, 2000, pp. 169190.

[41] Yethon J.A., Gunn J.S., Ernst R.K., Miller S.I., Laroche L., Malo D., Whitfield C., Salmonella enterica serovar Typhimurium waa $\mathrm{P}$ mutants show increased susceptibility to polymyxin and loss of virulence in vivo, Infect. Immun. (2000) 68:4485-4491.

[42] Yoshida H., Bogaki M., Nakamura M., Nakamura S., Quinolone resistantdetermining region in the DNA gyrase gyrA gene of Escherichia coli, Antimicrob. Agents Chemother. (1990) 14:1271-1272. 